\title{
Relationship of serum carotenoids and retinol with anaemia among pre-school children in the northern mountainous region of Vietnam
}

\author{
Nguyen Cong Khan ${ }^{1,2, *}$, Phan Van Huan ${ }^{3}$, Nguyen Van Nhien ${ }^{3}$, Le Danh Tuyen ${ }^{3}$, \\ Saskia de Pee ${ }^{4}$ and Richard D Semba ${ }^{5}$ \\ 'Vietnam Food Safety Administration, 138A Giang Vo, Badinh, Hanoi, Vietnam: ${ }^{2}$ Hanoi School of Public \\ Health, Hanoi, Vietnam: ${ }^{3}$ National Institute of Nutrition, Hanoi, Vietnam: ${ }^{4}$ Helen Keller International Asia Pacific, \\ Singapore: ${ }^{5}$ Department of Ophthalmology, Johns Hopkins University School of Medicine, Baltimore, MD, USA
}

Submitted 12 May 2009: Accepted 2 February 2010: First published online 29 June 2010

\begin{abstract}
Objective: To characterize the relationship between serum carotenoids, retinol and anaemia among pre-school children.

Design: A cross-sectional study was conducted in two groups: anaemic and non-anaemic. Serum levels of retinol, $\alpha$-carotene, $\beta$-carotene, $\beta$-cryptoxanthin, lycopene, lutein and zeaxanthin were measured in the study subjects.

Setting: Six rural communes of Dinh Hoa, a rural and mountainous district in Thai Nguyen Province, in the northern mountainous region of Vietnam.

Subjects: A total of 682 pre-school children, aged 12-72 months, were recruited. Results: Geometric mean serum concentrations of carotenoids $(\mu \mathrm{mol} / \mathrm{l})$ were 0.056 for $\alpha$-carotene, $0 \cdot 161$ for $\beta$-carotene, $0 \cdot 145$ for $\beta$-cryptoxanthin, 0.078 for lycopene, 0.388 for lutein and 0.075 for zeaxanthin. The mean levels of $\mathrm{Hb}$ and serum retinol were $108.8 \mathrm{~g} / \mathrm{l}$ and $1.02 \mu \mathrm{mol} / \mathrm{l}$, respectively. The prevalence of anaemia and vitamin A deficiency was $53 \cdot 7 \%$ and $7 \cdot 8 \%$, respectively. After adjusting for sex and stunting, serum retinol concentrations $(\mu \mathrm{mol} / \mathrm{l}$; OR $=2 \cdot 06$, $95 \%$ CI $1 \cdot 10,3 \cdot 86, P=0.024)$ and total provitamin A carotenoids $(\mu \mathrm{mol} / \mathrm{l}$; OR $=1 \cdot 52,95 \%$ CI $1 \cdot 01,2 \cdot 28, P=0 \cdot 046)$ were independently associated with anaemia, but non-provitamin A carotenoids ( $\mu \mathrm{mol} / \mathrm{l}$; OR $=0.93,95 \% \mathrm{CI} 0 \cdot 63$, $1 \cdot 37, P=0 \cdot 710)$ were not associated with anaemia.

Conclusions: Among pre-school children in the northern mountainous region of Vietnam, the prevalences of vitamin A deficiency and anaemia are high, and serum retinol and provitamin A carotenoids are independently associated with anaemia. Further studies are needed to determine if increased consumption of provitamin A carotenoids will reduce anaemia among pre-school children.
\end{abstract}

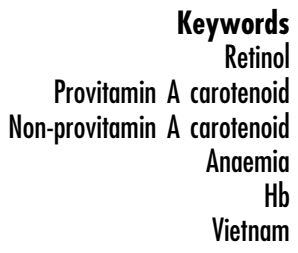

eywords

otenoid

mamia

Vietnam
Vitamin A deficiency and iron-deficiency anaemia are public health problems in developing countries and are associated with growth retardation, delayed cognitive development, depressed immune responses, higher risk of xerophthalmia and blindness, and increased morbidity and mortality ${ }^{(1,2)}$. Worldwide, vitamin A deficiency affects an estimated 140 million children under 5 years of age ${ }^{(3)}$.

Vitamin A deficiency is associated with anaemia. The biological mechanisms by which vitamin A deficiency contributes to anaemia is through impairment of erythropoiesis and iron metabolism and through reduced immunity and increased anaemia of infection ${ }^{(1)}$. Although many previous studies have shown an association between vitamin A deficiency and anaemia ${ }^{(4,5)}$ and between serum retinol and indicators of iron status ${ }^{(4,6)}$, less has been done to characterize the relationship between serum carotenoids and anaemia. Provitamin A carotenoid status reflects the intake of provitamin A carotenoids and is hence likely to be related to vitamin A status because the human body can convert these provitamin A carotenoids into the active form of vitamin A, retinol and its derivatives ${ }^{(7)}$. The relationship between carotenoids and anaemia may be important because, in developing countries, an estimated $70-90 \%$ of the total vitamin A intake is from provitamin A carotenoids ( $\alpha$-carotene, $\beta$-carotene and $\beta$-cryptoxanthin) in fruits and vegetables ${ }^{(8)}$. Therefore, foods rich in carotenoids are the main source of vitamin A for children in developing countries.

Previous studies have shown an association of vitamin A and serum provitamin A carotenoids with anaemia among pre-school children ${ }^{(1,9,10)}$. Thus, the present study 
Table 1 Characteristics of the Vietnamese pre-school children by age category

\begin{tabular}{|c|c|c|c|c|c|c|c|c|c|c|c|c|c|}
\hline & & & \multicolumn{10}{|c|}{ Age category (months) } & \multirow[b]{2}{*}{$P^{*}$} \\
\hline & \multicolumn{2}{|c|}{ Total } & \multicolumn{2}{|c|}{12 to $<24$} & \multicolumn{2}{|c|}{24 to $<36$} & \multicolumn{2}{|c|}{36 to $<48$} & \multicolumn{2}{|c|}{48 to $<60$} & \multicolumn{2}{|c|}{60 to $<72$} & \\
\hline \multirow[t]{2}{*}{$\begin{array}{l}n \\
\% \text { female }\end{array}$} & \multicolumn{2}{|c|}{$\begin{array}{c}682 \\
49 \cdot 3\end{array}$} & \multicolumn{2}{|c|}{$\begin{array}{c}117 \\
54 \cdot 7\end{array}$} & \multicolumn{2}{|c|}{$\begin{array}{c}150 \\
48 \cdot 7\end{array}$} & \multicolumn{2}{|c|}{$\begin{array}{c}116 \\
58 \cdot 6\end{array}$} & \multicolumn{2}{|c|}{$\begin{array}{c}147 \\
46 \cdot 3\end{array}$} & \multicolumn{2}{|c|}{$\begin{array}{c}152 \\
41 \cdot 4\end{array}$} & 0.045 \\
\hline & Mean & SD & Mean & SD & Mean & SD & Mean & SD & Mean & SD & Mean & SD & \\
\hline Age (months) & $43 \cdot 0$ & $17 \cdot 5$ & $17 \cdot 7$ & $3 \cdot 4$ & $29 \cdot 8$ & $3 \cdot 9$ & $41 \cdot 6$ & $3 \cdot 9$ & $53 \cdot 8$ & $3 \cdot 7$ & $66 \cdot 0$ & $3 \cdot 7$ & $<0.0001$ \\
\hline Weight $(\mathrm{kg})$ & $12 \cdot 1$ & $2 \cdot 6$ & $8 \cdot 7$ & $1 \cdot 0$ & $10 \cdot 7$ & $1 \cdot 1$ & $12 \cdot 1$ & $1 \cdot 3$ & $13 \cdot 5$ & $1 \cdot 6$ & $15 \cdot 0$ & $1 \cdot 6$ & $<0.0001$ \\
\hline Height $(\mathrm{cm})$ & $91 \cdot 9$ & $10 \cdot 9$ & $75 \cdot 9$ & $3 \cdot 5$ & $85 \cdot 3$ & $4 \cdot 8$ & $92 \cdot 2$ & $5 \cdot 1$ & $98 \cdot 1$ & $4 \cdot 6$ & $104 \cdot 4$ & $4 \cdot 7$ & $<0.0001$ \\
\hline WAZ & $-1 \cdot 94$ & 0.77 & -1.99 & $0 \cdot 82$ & $-1 \cdot 88$ & $0 \cdot 76$ & $-1 \cdot 90$ & 0.75 & $-1 \cdot 98$ & $0 \cdot 81$ & $-1 \cdot 96$ & $0 \cdot 70$ & $0 \cdot 705$ \\
\hline HAZ & $-1 \cdot 58$ & $1 \cdot 13$ & $-1 \cdot 69$ & $1 \cdot 19$ & $-1 \cdot 26$ & $1 \cdot 27$ & $-1 \cdot 50$ & $1 \cdot 26$ & $-1 \cdot 76$ & 0.93 & $-1 \cdot 71$ & 0.96 & 0.001 \\
\hline WHZ & $-1 \cdot 28$ & $0 \cdot 79$ & $-1 \cdot 37$ & $0 \cdot 79$ & $-1 \cdot 26$ & $0 \cdot 81$ & $-1 \cdot 25$ & $0 \cdot 79$ & $-1 \cdot 26$ & $0 \cdot 84$ & $-1 \cdot 28$ & $0 \cdot 73$ & $0 \cdot 746$ \\
\hline
\end{tabular}

WAZ, weight-for-age $Z$-score; $\mathrm{HAZ}$, height-for-age Z-score; WHZ, weight-for-height Z-score.

${ }^{*} P$ value from ANOVA.

aimed to characterize serum retinol and carotenoids and anaemia among pre-school children in a rural region of northern Vietnam.

\section{Subjects and methods}

A cross-sectional study was conducted from October to November 2003 in six rural communes of Dinh Hoa, a rural and mountainous district in Thai Nguyen Province, in the northern mountainous region of Vietnam, situated $170 \mathrm{~km}$ north of Hanoi. A total of 682 pre-school children aged 12-72 months were randomly chosen by cluster from lists of subjects which were provided by local health centres. The study subjects were enrolled in the study after written informed consent was obtained from the parent or guardian. Study physicians examined all children. Only those who were free from chronic, acute illness and congenital abnormality were included.

Body weight was determined to the nearest $0 \cdot 1 \mathrm{~kg}$, while children were minimally clothed, with a paediatric scale for children (SECA beam balance, Hamburg, Germany). Length of children $<24$ months of age or height of children $>24$ months was measured to the nearest $0 \cdot 1 \mathrm{~cm}$. Z-scores of the indicators weight-for-age (WAZ), height/length-for-age (HAZ) and weight-for-height/length (WHZ) were calculated with EPI-INFO version $3 \cdot 3 \cdot 2$ (Centers for Disease Control and Prevention, Atlanta, GA, USA), using the National Center for Health Statistics data as a reference ${ }^{(11)}$.

Blood samples were collected in the morning (07.0011.00 hours). Three millilitres of venous blood were drawn into sterile polypropylene tubes. The tubes were kept in the dark in a cool box $\left(0-4^{\circ} \mathrm{C}\right)$ and transported to the district health centre within $5 \mathrm{~h}$. Sera were separated from cells by centrifugation at $3000 \mathrm{~g}$ for $10 \mathrm{~min}$ at $4^{\circ} \mathrm{C}$. Aliquots of serum were stored at $-70^{\circ} \mathrm{C}$ until analysis.

$\mathrm{Hb}$ was determined in whole blood using the cyanmethaemoglobin method ${ }^{(12)}$. Retinol was analysed by HPLC (HPLC model LC 10ADvp; Shimadzu, Tokyo, Japan) in a darkened room at the National Institute of Nutrition,
Hanoi, Vietnam ${ }^{(13)}$. Serum carotenoids were measured using reverse-phase HPLC ${ }^{(14)}$ at Johns Hopkins University School of Medicine, Baltimore, MD, USA. Pooled human sera were used to measure intra- and inter-assay $\mathrm{CV}$ in laboratory analyses. For $\alpha$-carotene, $\beta$-carotene, $\beta$-cryptoxanthin, lycopene, lutein and zeaxanthin, the within-assay and betweenassay CV were $11 \%$ and $12 \%, 8 \%$ and $8 \%, 6 \%$ and $5 \%$, $12 \%$ and $8 \%, 6 \%$ and $6 \%$, and $15 \%$ and $15 \%$, respectively. Children with $\mathrm{Hb}$ concentration lower than $80 \mathrm{~g} / 1$ were referred to the health centre of the district for treatment. The Institutional Review Board of the National Institute of Nutrition and the Ministry of Health, Hanoi, Vietnam approved the study protocol.

All data were analysed using the SPSS for Windows statistical software package version $11 \cdot 0$ (SPSS, Inc., Chicago, IL, USA). A one-sample Kolmogorov-Smirnov test was used to assess whether the data were normally distributed. When data were not normally distributed, statistical analysis was carried out after log transformation. For continuous response variables, results are presented as means and standard deviations or as geometric means for log-transformed data. Anaemia was defined as $\mathrm{Hb}<110 \mathrm{~g} / 1$ for children aged 12-60 months and as $\mathrm{Hb}<115 \mathrm{~g} / 1$ for children aged 60-72 months ${ }^{(12)}$. The subjects who had anaemia were classified as the anaemic group while the others were designated the non-anaemic group. Vitamin A deficiency was defined as serum retinol concentration $<0 \cdot 70 \mu \mathrm{mol} / \mathrm{l}^{(13)}$. Provitamin A carotenoids were defined as the sum of $\alpha$-carotene, $\beta$-carotene and $\beta$-cryptoxanthin in $\mu \mathrm{mol} / 1$, and non-provitamin A carotenoids were defined as the sum of lutein, zeaxanthin and lycopene in $\mu \mathrm{mol} / \mathrm{l}$. The independent-samples $t$ test and one-way ANOVA with post hoc analysis (Tukey's honestly significant difference) were used to determine the differences in anthropometric, carotenoid levels and biochemical indicators between anaemic and non-anaemic group, sexes and age categories. Univariate and multivariate logistic regression analyses were used to estimate the relative risks of factors associated with anaemia. Regression coefficients were converted to odds ratios, 


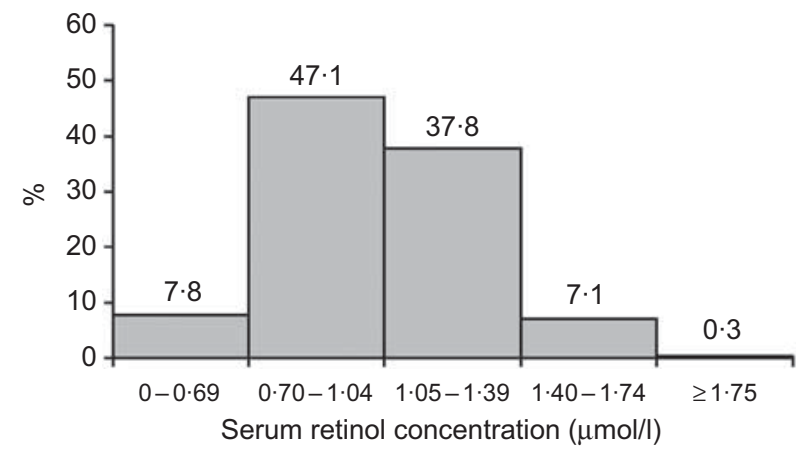

Fig. 1 Frequency distribution of serum retinol concentrations in 678 pre-school children in the northern mountainous region of Vietnam

and the confidence intervals for the odds ratios were derived from the standard error estimates of the regression coefficients. For all analyses the level of significance was $P<0 \cdot 05$.

\section{Results}

A total of 682 pre-school children from the six communes were included in the study. Of these children, 676 had serum carotenoids measured, 678 had serum retinol measured and 681 children had $\mathrm{Hb}$ measured. The mean age of the 682 children was 43.0 (SD 17.5) months, and there were 346 boys and 336 girls. Mean WAZ was -1.94 (SD 0.77), mean HAZ was -1.58 (SD 1.13) and mean WHZ was $-1 \cdot 28$ (SD 0.79; Table 1$)$. The prevalence of children with WAZ, HAZ and WHZ $<-2$ was $46 \cdot 3 \%(316 / 682)$, $32 \cdot 0 \%(218 / 682)$ and $16 \cdot 0 \%(109 / 682)$, respectively. Children were divided into 12-month age categories between 12 and 72 months of age. The prevalence of underweight and wasting was not different between the five age categories $(P>0 \cdot 05)$. However, there were significant differences in the prevalence of stunting among the five age categories $(P=0 \cdot 002)$. This prevalence was highest in the age group of 48 to $<60$ months $(38 \cdot 8 \%)$ but lowest in age group of 24 to $<36$ months (19.3\%).

Mean serum vitamin A of the study population was 1.02 (SD 0.26) $\mu \mathrm{mol} / \mathrm{l}$, and the overall prevalence of vitamin A deficiency was $7 \cdot 8 \%$ (53/678; Table 2$)$. However, a large proportion of the children $(47 \cdot 1 \%)$ had serum retinol in the range of $0 \cdot 70-1 \cdot 04 \mu \mathrm{mol} / 1$, thus just above the cut-off level for vitamin A deficiency (Fig. 1). The mean Hb concentration was 108.8 (SD 11.6) g/l. Hb levels among boys ( $n$ 345) and girls ( $n$ 336) were 109.6 (sD 11.5) and 108.1 (sD 11.5) g/l, respectively, and were not statistically different $(P=0 \cdot 10)$. Of the total population of children, $53 \cdot 7 \%(366 / 681)$ were found to be anaemic (Table 2). The mean ages of children with and without anaemia were 41.0 (SD 18.7) and 45.3 (SD 15.7) months, respectively $(P=0 \cdot 001)$.

The serum concentrations of $\alpha$-carotene, $\beta$-carotene, $\beta$-cryptoxanthin, lycopene, lutein, zeaxanthin, provitamin A 
carotenoids and non-provitamin A carotenoids, among the pre-school children by age category, are shown in Table 3. Serum concentrations of $\alpha$-carotene, $\beta$-carotene, lycopene and total provitamin A carotenoids were significantly higher at older age, while serum concentrations of lutein, zeaxanthin and total non-provitamin A carotenoids were significantly lower with increasing age. However, there was no trend in serum $\beta$-cryptoxanthin level by age among these subjects.

Carotenoids were classified into two main groups as provitamin A carotenoids ( $\alpha$-carotene, $\beta$-carotene and $\beta$-cryptoxanthin) and non-provitamin A carotenoids (lycopene, lutein and zeaxanthin). Children with anaemia had significantly lower serum levels of retinol and geometric mean levels of $\alpha$-carotene, $\beta$-carotene, $\beta$-cryptoxanthin, provitamin A carotenoids, lycopene and zeaxanthin, compared with children without anaemia. On other hand, there were no significant differences in geometric mean serum concentrations of lutein and non-provitamin A carotenoids between children with and without anaemia (Table 4).

Serum retinol and carotenoid concentrations were compared between boys and girls; there were no significant differences in mean or geometric mean serum concentrations of any of the micronutrients by gender (data not shown).

Multivariate logistic regression analysis was used to examine the relationship between retinol, provitamin A carotenoids and non-provitamin A carotenoids and anaemia (Table 5). After adjusting for gender and stunting, serum retinol concentrations $(\mu \mathrm{mol} / \mathrm{l} ; \mathrm{OR}=2 \cdot 06,95 \%$ CI $1 \cdot 10$, $3 \cdot 86, P=0.024)$ and provitamin A carotenoids ( $\mu \mathrm{mol} / \mathrm{l}$; $\mathrm{OR}=1 \cdot 52,95 \%$ CI $1 \cdot 01,2 \cdot 28, P=0 \cdot 046)$ were independently associated with anaemia, but non-provitamin A carotenoids $(\mu \mathrm{mol} / \mathrm{l}$; OR $=0.93,95 \%$ CI $0.63,1 \cdot 37$, $P=0 \cdot 710)$ were not associated with anaemia.

\section{Discussion}

The present study is the first to describe the major serum carotenoids among pre-school children in Vietnam, and also is one of the very few studies about carotenoid status in developing countries ${ }^{(15,16)}$. The data showed that serum carotenoid concentrations were very low among pre-school children in the north mountainous region in Vietnam. The geometric mean carotenoid concentration for $\alpha$-carotene, $\beta$-carotene and $\beta$-cryptoxanthin among Vietnamese children was similar to the 25 th percentiles among 839 children aged 6-7 years who participated in the third National Health and Nutrition Examination Survey in the USA between 1988 and 1994 ( $\mu \mathrm{mol} / 1$ : 0.030 for $\alpha$-carotene, 0.206 for $\beta$-carotene and 0.131 for $\beta$-cryptoxanthin, and 5 th percentile for lycopene of $0 \cdot 167)^{(17)}$. The values observed among the Vietnamese children were also similar to the 25th percentile for 493 children in Belize, aged 25-115 months ( $\mu \mathrm{mol} / \mathrm{l}$ : 0.056 for

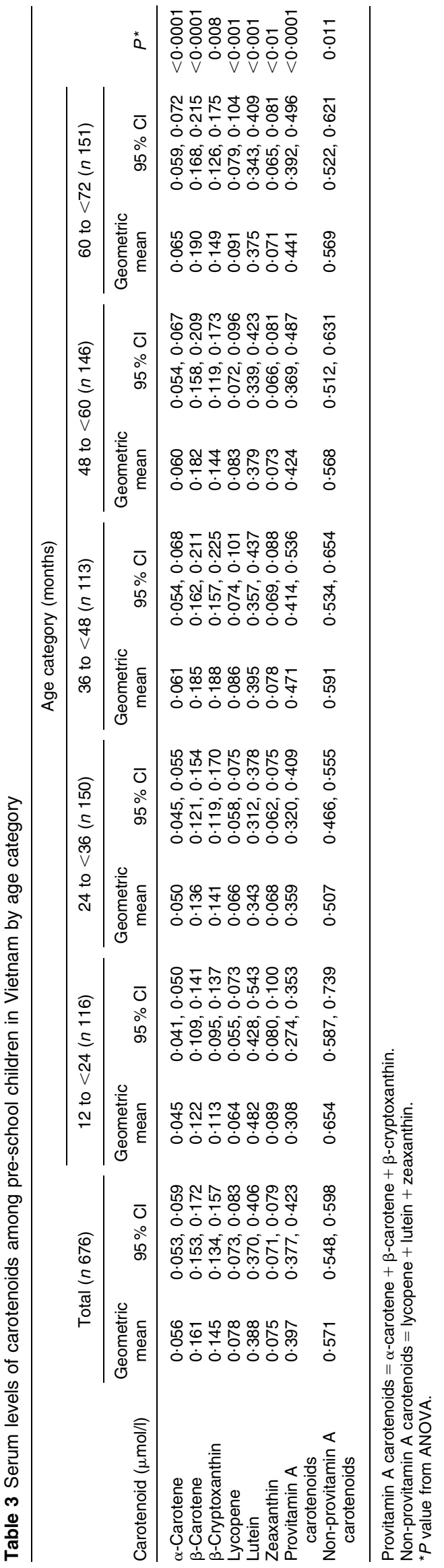


Table 4 Serum levels of micronutrients among pre-school children in Vietnam with and without anaemia

\begin{tabular}{|c|c|c|c|c|c|}
\hline & \multicolumn{2}{|c|}{ Anaemic group } & \multicolumn{2}{|c|}{ Non-anaemic group } & \multirow[b]{2}{*}{$P^{*}$} \\
\hline & $n$ & $\%$ & $n$ & $\%$ & \\
\hline \multirow{3}{*}{$\begin{array}{l}\text { Male gender } \\
\text { Female gender }\end{array}$} & 177 & $51 \cdot 3$ & 168 & $48 \cdot 7$ & $0 \cdot 196$ \\
\hline & 189 & $56 \cdot 3$ & 147 & $43 \cdot 7$ & $0 \cdot 196$ \\
\hline & Mean & SD & Mean & SD & \\
\hline Age (months) & $41 \cdot 0$ & $18 \cdot 7$ & $45 \cdot 3$ & $15 \cdot 7$ & 0.001 \\
\hline WAZ & $-2 \cdot 00$ & 0.75 & $-1 \cdot 87$ & 0.78 & 0.025 \\
\hline HAZ & $-1 \cdot 69$ & $1 \cdot 21$ & $-1 \cdot 46$ & $1 \cdot 03$ & $0 \cdot 007$ \\
\hline WHZ & $-1 \cdot 29$ & $0 \cdot 80$ & $-1 \cdot 28$ & 0.78 & $0 \cdot 874$ \\
\hline $\mathrm{Hb}(\mathrm{g} / \mathrm{l})$ & $100 \cdot 5$ & $8 \cdot 3$ & $118 \cdot 5$ & $6 \cdot 1$ & $<0.0001$ \\
\hline \multirow[t]{2}{*}{ Retinol $(\mu \mathrm{mol} / \mathrm{l})$} & $1 \cdot 00$ & $0 \cdot 24$ & $1 \cdot 05$ & $0 \cdot 28$ & 0.017 \\
\hline & Geometric mean & $95 \% \mathrm{Cl}$ & Geometric mean & $95 \% \mathrm{Cl}$ & \\
\hline$\alpha$-Carotene $(\mu \mathrm{mol} / \mathrm{l})$ & 0.053 & $0.050,0.056$ & $0 \cdot 060$ & $0.056,0.064$ & $0 \cdot 012$ \\
\hline$\beta$-Carotene $(\mu \mathrm{mol} / \mathrm{l})$ & $0 \cdot 150$ & $0 \cdot 138,0 \cdot 163$ & $0 \cdot 178$ & $0 \cdot 164,0 \cdot 193$ & 0.006 \\
\hline$\beta$-Cryptoxanthin ( $\mu \mathrm{mol} / \mathrm{l})$ & $0 \cdot 127$ & $0 \cdot 113,0 \cdot 142$ & $0 \cdot 169$ & $0 \cdot 152,0 \cdot 189$ & 0.0003 \\
\hline Lycopene $(\mu \mathrm{mol} / \mathrm{i})$ & 0.073 & $0.066,0.080$ & $0 \cdot 084$ & $0.076,0.092$ & 0.034 \\
\hline Lutein $(\mu \mathrm{mol} / \mathrm{l})$ & $0 \cdot 381$ & $0.357,0.406$ & 0.399 & $0.374,0.427$ & $0 \cdot 384$ \\
\hline Zeaxanthin $(\mu \mathrm{mol} / \mathrm{l})$ & $0 \cdot 071$ & $0.067,0.075$ & $0 \cdot 080$ & $0.075,0.086$ & $0 \cdot 012$ \\
\hline Provitamin A carotenoids ( $\mu \mathrm{mol} / \mathrm{l})$ & $0 \cdot 364$ & $0.336,0.396$ & $0 \cdot 444$ & $0 \cdot 410,0 \cdot 480$ & $0 \cdot 001$ \\
\hline Non-provitamin A carotenoids ( $\mu \mathrm{mol} / \mathrm{l})$ & 0.557 & $0.523,0.592$ & 0.595 & $0.559,0.633$ & $0 \cdot 179$ \\
\hline
\end{tabular}

WAZ, weight-for-age Z-score; HAZ, height-for-age Z-score; WHZ, weight-for-height Z-score.

Provitamin A carotenoids $=\alpha$-carotene $+\beta$-carotene $+\beta$-cryptoxanthin.

Non-provitamin A carotenoids = lycopene + lutein + zeaxanthin

${ }^{*} P$ value from independent-samples $t$ test.

Table 5 Univariate and multivariate models of factors associated with anaemia in Vietnamese pre-school children

\begin{tabular}{|c|c|c|c|c|c|c|}
\hline \multirow[b]{2}{*}{ Characteristic } & \multicolumn{3}{|c|}{ Univariate model } & \multicolumn{3}{|c|}{ Multivariate model } \\
\hline & OR & $95 \% \mathrm{Cl}$ & $P$ & OR & $95 \% \mathrm{Cl}$ & $P$ \\
\hline Gender & $0 \cdot 82$ & $0 \cdot 61,1 \cdot 11$ & $0 \cdot 196$ & $0 \cdot 80$ & $0 \cdot 58,1 \cdot 08$ & $0 \cdot 144$ \\
\hline Stunting & $1 \cdot 33$ & $0.88,2.02$ & $0 \cdot 179$ & $1 \cdot 20$ & $0.78,1 \cdot 84$ & $0 \cdot 401$ \\
\hline Serum retinol* & $2 \cdot 09$ & $1 \cdot 13,3 \cdot 85$ & $0 \cdot 018$ & $2 \cdot 06$ & $1 \cdot 10,3 \cdot 86$ & 0.024 \\
\hline Provitamin A carotenoidst & 1.53 & $1 \cdot 07,2 \cdot 21$ & 0.021 & $1 \cdot 52$ & $1 \cdot 01,2 \cdot 28$ & 0.046 \\
\hline Non-provitamin A carotenoids $\ddagger$ & $1 \cdot 12$ & $0.80,1.58$ & 0.512 & 0.93 & $0.63,1.37$ & $0 \cdot 710$ \\
\hline
\end{tabular}

*Serum retinol in $\mu \mathrm{mol} / \mathrm{l}$.

†Provitamin A carotenoids $=\alpha$-carotene $+\beta$-carotene $+\beta$-cryptoxanthin $(\mu \mathrm{mol} / \mathrm{l})$.

¥Non-provitamin A carotenoids = lycopene + lutein + zeaxanthin $(\mu \mathrm{mol} / \mathrm{l})$.

$\alpha$-carotene, $0 \cdot 130$ for $\beta$-carotene, $0 \cdot 090$ for $\beta$-cryptoxanthin and 0.056 for lycopene $)^{(18)}$. However, the geometric mean concentrations of serum carotenoids of Vietnamese children were higher than those described among 278 children aged $1-5$ years in the Marshall Islands ${ }^{(14)}$. The low serum concentrations of carotenoids in pre-school children in Vietnam may be the consequence of poor dietary intakes of lipids and carotene-rich foods ${ }^{(19)}$.

The total prevalence of vitamin A deficiency was $7 \cdot 8 \%$ in the study population, which indicates that vitamin A deficiency is still a public health problem in Vietnam. Vitamin A capsule distribution programmes are the main strategy for reducing vitamin A deficiency in many developing countries $^{(20)}$. Annually Vietnamese children receive high-dose vitamin A capsules through two distribution campaigns throughout the effective network of existing preventive health infrastructure at all administrative levels, with a coverage rate of $70-90 \%$ at national level ${ }^{(21)}$. Therefore, it appears that the prevalence of vitamin A deficiency decreased from $12 \%$ in the year $2000^{(22)}$ to about $8 \%$ in the present study, but this finding is not absolutely conclusive since the same study populations were not sampled in the two different years. The prevalence of anaemia was also extremely high in the present study, occurring in $53.7 \%$ of the pre-school children. This prevalence of anaemia is higher than the global estimates for pre-school children (42\%) in developing countries ${ }^{(23)}$. This may be the consequence of poor iron stores of children due to too low consumption of iron-rich foods, poor iron status of the mother ${ }^{(19)}$ and the high prevalence of hookworm infection in Vietnam $(28 \cdot 6 \%)^{(24)}$. That both vitamin A deficiency and anaemia are still highly prevalent in the studied site indicates a challenge for the reduction of micronutrient deficiencies in poor areas such as mountainous regions in the country.

In agreement with results from previous studies, our study showed that serum retinol concentrations are positively correlated with $\mathrm{Hb}$ concentrations ${ }^{(1,5,10,16)}$. 
Vitamin A deficiency impairs Hb synthesis and depresses erythropoiesis $^{(25,26)}$. This was most clearly demonstrated in a clinical experiment involving anaemic adults who were depleted of vitamin A, in whom supplementation with vitamin A improved $\mathrm{Hb}$ levels or iron status ${ }^{(25)}$. Furthermore, several intervention studies have shown that vitamin A supplementation improves $\mathrm{Hb}$ response, such as a study in Malawian infants, in schoolchildren in Tanzania and in pregnant Indonesian women ${ }^{(27-30)}$. Multiple logistic regression analyses were used to determine the factors related to anaemia in the present study. Anaemic children had significantly lower levels of vitamin A, $\alpha$-carotene, $\beta$-carotene, $\beta$-cryptoxanthin and provitamin A carotenoids compared with non-anaemic children, suggesting that provitamin A carotenoids play a greater role than non-provitamin A carotenoids in anaemia among these pre-school children.

In conclusion, the present study showed that the prevalence of both vitamin A deficiency and anaemia are high among pre-school children in the northern mountainous region of Vietnam. Both serum retinol and serum provitamin A carotenoids are independently associated with anaemia. Further studies are needed to determine whether increasing the intake of provitamin A carotenoids will have an impact on anaemia.

\section{Acknowledgements}

The research team gratefully acknowledges the Nestlé Foundation and Helen Keller International for funding support. The authors have no conflicts of interest. N.C.K. and R.D.S. were the principal investigators of the study; they were responsible for the design of the study, the supervision of the biochemical measurements and the preparation of the manuscript. P.V.H. was responsible for conducting the survey and data management and analysis. N.V.N. was responsible for conducting the survey, the analysis of $\mathrm{Hb}$ and vitamin $\mathrm{A}$, data management and analysis, and preparation of the manuscript. S.d.P. participated in the development of the study protocol, the evaluation of the results and contributed to the preparation of the manuscript. We thank the health workers, the local officials of the six communes and the research staff of the Community Nutrition Department of the National Institute of Nutrition, Vietnam and of the Health Centre of Dinh Hoa District, Thai Nguyen Province for their help during the data collection and organization. More important, the team is greatly indebted to the children and their families who allowed a glimpse of their lives.

\section{References}

1. Semba RD \& Bloem MW (2002) The anemia of vitamin A deficiency: epidemiology and pathogenesis. Eur J Clin Nutr 56, 271-281.
2. Sommer A \& West KP Jr (1996) Vitamin A Deficiency: Health, Survival, and Vision. New York: Oxford University Press.

3. Sommer A \& Davidson FR (2002) Assessment and control of vitamin A deficiency: the Annecy Accords. J Nutr 132, 9 Suppl., 2845S-2850S.

4. Bloem MW, Wedel M, Egger RJ et al. (1989) Iron metabolism and vitamin A deficiency in children in northeast Thailand. Am J Clin Nutr 50, 332-338.

5. Van Nhien N, Khan NC, Ninh NX et al. (2008) Micronutrient deficiencies and anemia among pre-school children in rural Vietnam. Asia Pac J Clin Nutr 17, 48-55.

6. Mejia LA \& Arroyave G (1982) The effect of vitamin A fortification of sugar on iron metabolism in pre-school children in Guatemala. Am J Clin Nutr 36, 87-93.

7. van Poppel G (1996) Epidemiological evidence for $\beta$ carotene in prevention of cancer and cardiovascular disease. Eur J Clin Nutr 50, Suppl. 3, S57-S61.

8. Food and Agriculture Organization of the United Nations (1988) Requirements of Vitamin A, Iron, Folate and Vitamin $B_{12}$. Report of a Joint FAO/WHO Expert Consultation. FAO Food and Nutrition Series no. 23. Rome: FAO.

9. Nussenblatt V, Mukasa G, Metzger A et al. (2002) Relationship between carotenoids and anaemia during acute uncomplicated Plasmodium falciparum malaria in children. J Health Popul Nutr 20, 205-214.

10. Palafox NA, Gamble MV, Dancheck B et al. (203) Vitamin A deficiency, iron deficiency, and anemia among pre-school children in the Republic of the Marshall Islands. Nutrition 19, 405-408.

11. National Center for Health Statistics (1977) NCHS Growth Curves for Children, Birth-18 Years, United States. Washington, DC: US Department of Health, Education and Welfare.

12. World Health Organization (2001) Iron Deficiency Anaemia: Assessment, Prevention, and Control. Geneva: WHO.

13. International Vitamin A Consultative Group (1982) Biochemical Methodology for Assessment of Vitamin A Status. Washington, DC: The Nutrition Foundation.

14. Gamble MV, Palafox NA, Dancheck B et al. (2004) Carotenoid status among pre-school children with vitamin A deficiency in the Republic of the Marshall Islands. Asia Pac J Clin Nutr 13, 336-340.

15. de Pee S, West CE, Permaesih D et al. (1998) Orange fruit is more effective than are dark-green, leafy vegetables in increasing serum concentrations of retinol and betacarotene in schoolchildren in Indonesia. Am J Clin Nutr 68, 1058-1067.

16. Gamble MV, Palafox NA, Dancheck B et al. (2004) Relationship of vitamin A deficiency, iron deficiency, and inflammation to anemia among preschool children in the Republic of the Marshall Islands. Eur J Clin Nutr 58, 1396-1401.

17. Ford ES, Gillespie C, Ballew C et al. (2002) Serum carotenoid concentrations in US children and adolescents. Am J Clin Nutr 76, 818-827.

18. Apgar J, Makdani D, Sowell AL et al. (1996) Serum carotenoid concentrations and their reproducibility in children in Belize. Am J Clin Nutr 64, 726-730.

19. National Institute of Nutrition/UNICEF/Centers for Disease Control and Prevention (1995) Report of the National Anemia and Nutrition Risk Factor Survey, Vietnam 1995. Program Against Micronutrient Malnutrition, pp. 13-30. Hanoi: NIN, Vietnam/UNICEF-Vietnam/CDC.

20. McLaren DS \& Frigg M (2001) Sight and Life Manual on Vitamin A Deficiency Disorders (VAD), 2nd ed. Basel: Task Force Sight and Life.

21. Khan NC, Khoi HH, Giay T et al. (2002) Control of vitamin A deficiency in Vietnam: achievements and future orientation. Food Nutr Bull 23, 133-142. 
22. World Health Organization (2009) Global prevalence of vitamin A deficiency in populations at risk 1995-2005. WHO Global Database on Vitamin A Deficiency. Geneva: WHO.

23. United Nations Administrative Committee on Coordination, Sub-committee on Nutrition (2000) Fourth Report on the World Nutrition Situation. Geneva: ACC/SCN in collaboration with IFPRI.

24. van der Hoek W, De NV, Konradsen F et al. (2003) Current status of soil-transmitted helminths in Vietnam. Southeast Asian J Trop Med Public Health 34, Suppl. 1, 1-11.

25. Hodges RE, Sauberlich HE, Canham JE et al. (1978) Hematopoietic studies in vitamin A deficiency. Am J Clin Nutr 31, 876-885.

26. Allen LH (2002) Iron supplements: scientific issues concerning efficacy and implications for research and programs. J Nutr 132, 4 Suppl., 813S-819S.
27. Suharno D, West CE, Muhilal et al. (1993) Supplementation with vitamin A and iron for nutritional anaemia in pregnant women in West Java, Indonesia. Lancet 342 , $1325-1328$.

28. Muslimatun S, Schmidt MK, Schultink W et al. (2001) Weekly supplementation with iron and vitamin A during pregnancy increases hemoglobin concentration but decreases serum ferritin concentration in Indonesian pregnant women. J Nutr 131, 85-90.

29. Mwanri L, Worsley A, Ryan P et al. (2000) Supplemental vitamin A improves anemia and growth in anemic school children in Tanzania. J Nutr 130, 2691-2696.

30. Kumwenda N, Miotti PG, Taha TE et al. (2002) Antenatal vitamin A supplementation increases birth weight and decreases anemia among infants born to human immunodeficiency virus-infected women in Malawi. Clin Infect Dis 35, 618-624. 